\title{
AN OPTIMIZATION APPROACH TO THE INTERMODAL TRANSPORTATION NETWORK IN FRUIT COLD CHAIN, CONSIDERING COST, QUALITY DEGRADATION AND CARBON DIOXIDE FOOTPRINT
}

\author{
Qianli Ma \\ Wenyuan Wang \\ Yun Peng \\ Xiangqun Song \\ Dalian University of Technology, Dalian, China
}

\begin{abstract}
This model optimizes port hinterland intermodal refrigerated container flows, considering both cost and quality degradation, which is distinctive from the previous literature content in a way that it quantifies the influence of carbon dioxide $\left(\mathrm{CO}_{2}\right)$ emission in different setting temperature on intermodal network planning. The primary contribution of this paper is that the model is beneficial not only to shippers and customers for the novel service design, but also offer, for policy-makers of the government, insights to develop inland transport infrastructures in consideration of intermodal transportation. The majority of models of multimodal system have been established with an objective of cost minimization for normal commodities. As the food quality is possible to be influenced by varying duration time required for the storage and transportation, and transportation accompanied with refrigeration producing more $\mathrm{CO}_{2}$ emission, this paper aims to address cost minimization and quality degradation minimization within the constraint of $\mathrm{CO}_{2}$ footprint. To achieve this aim, we put the quality degradation model in a mixed-integer linear programming model used for intermodal network planning for cold chain. The example of Dalian Port and Yingkou Port offer insight into trade-offs between transportation temperature and transport mode considering $\mathrm{CO}_{2}$ footprint. Furthermore, the model can offer a useful reference for other regions with the demand for different imported food, which requires an uninterrupted cold chain during the transportation and storage.
\end{abstract}

Keywords: intermodal transport network; quality model; refrigerated container; fruit cold chain; integer linear programming

\section{INTRODUCTION}

Global fruit and vegetable production has experienced remarkable growth with the rate of some 6 percent per annum over the past two decades. Transportation and storage of fresh fruits and fresh vegetables are challenging and risky operations due to the highly perishable nature of such products. Distribution of fresh products falls in the category of cold chains in which the products are conserved at low temperature. For $20 \%$ amount of the fruits and vegetables, an efficient cold chain is essential to preserve their quality and to their shelf life in order to reduce food losses. Moreover, lots of other food cargoes, such as seafood, dairy product, red wine and chocolate, are also traded across borders via cold chain transport. Compared with most supply chains, food cold chain is often more difficult and complex to manage because food is perishable and has a short shelf life.

Due to the rapid development of food cold chain and the enormous success of containerization, the use of refrigerated containers has shown a continuous growth during the past two decades. The massive growth of trade in refrigerated containers depends on many factors, mostly economic and technological. In China, to integrate into the Belt and Road $(B \& R)$ Initiative actively, Dalian Port and Yingkou Port have 
opened up some new international logistic channels, such as Liaoning-Manchuria-Europe Channel, Liaoning-Sea-Europe and China-South Korea-Russia. Especially, Dalian Port has opened a new domestic cold-chain model with refrigerated container train for sea-rail intermodal transport.

Intermodal transport is a term used to describe the movement of goods in an identical loading unit or vehicle which uses various modes of transport (road, rail, air and sea) successively without any handling of the freights themselves during transfers between modes. It can save time and money by integrating freight, simplifying complex loading and unloading steps, and protecting freight from extreme weather and damage (Min, 1991).

The scheduling of intermodal network for normal commodities has drawn a lot of interest in academic research field. The majority of models of intermodal network scheduling have been established with a single objective, such as cost minimization (Iannone and Thore, 2010; Wang and Yun, 2013), time minimization (Zhang et al., 2010) and $\mathrm{CO}_{2}$ emission (Liao et al., 2009). Some other authors integrated transit time, storage time or transportation distance into the multiple target system with a cost minimization (Yang et al., 2011; Zhang et al., 2011; Lam and Gu, 2016; Rahimi et al., 2008). However, with the food quality in the cold chain logistics gaining increasing attention, very few papers studied the design of intermodal network for refrigerated containers and took the quality level of the food in the refrigerated containers into consideration in targets of the optimization. For individual refrigerated containers, approximately 19\% of the energy use related to its journey is used for refrigeration purposes (Fitzgerald et al., 2011). Due to the importance of refrigeration and transportation to $\mathrm{CO}_{2}$ footprint, the environmental protection has become a key concern in the cold chain logistics.

Taking the research gaps into account, this paper develops a novel optimization model for the scheduling of the intermodal network of a container port hinterland. The final aim of this model is to put forward an innovative intermodal network scheduling which can help the shipper to achieve cost minimization, quality degradation minimization, and $\mathrm{CO}_{2}$ footprint to better meet market needs.

\section{PROBLEM DESCRIPTION}

\section{QUALITY DEGRADATION PROBLEM}

Generally, quality degradation of food in transport and storage is dependent on time $t$, temperature $\mathrm{T}$, and other constants (activation energy and gas constant), which can be described by the equation:

$$
\frac{d q}{d t}=k q^{n}
$$

Where $q$ is the quality, $k$ - the rate of decay, and $n$ - the power factor. For food where quality degradation is related to microbial growth (e.g., meat and fish), the quality degradation follows the first-order reactions shown by the line F in Fig. 1, while other food (e.g., fresh fruits and vegetables) follow the zero-order reactions shown by the line $\mathrm{Z}$.

Prediction of food quality is a complicated problem because of the range and diversity of food features and their transport and storage conditions. Plenty of models have been established for specific kinds of food (Vankerschaver et al., 1996; McDonald and Sun, 1999; Lukasse and Polderdijk, 2003). From the above mentioned models we can know that temperature is a leading factor affecting food quality in supply chains. The rate of quality degradation $k$ is dependent on the Arrhenius equation:

$$
k=k_{0} \cdot \exp \left[-E_{a} / R T\right]
$$

where $k_{0}$ is a constant, $E_{a}$ - the activation energy, $R$ - the gas constant, and $T$ - the absolute temperature.

We can estimate the food quality at a certain location, based on Eq. (1) dependent on an initial quality $q_{0}$, time interval $t_{i}$, degradation rate $k_{i}$ (related to $T_{i}$ ), getting:

$$
q=q_{0}-\sum_{i=1}^{m} k_{i} t_{i}
$$

for zero-order reactions and:

$$
q=q_{0} \cdot \exp \left[-\sum_{i=1}^{m} k_{i} t_{i}\right]
$$

for first-order reactions.

Substituting the Eq. (2) we get:

$$
q=q_{0}-\sum_{i=1}^{m} k_{0} t_{i} \cdot \exp \left[-E_{a} / R T_{i}\right]
$$

and:

$$
q=q_{0} \cdot \exp \left[-\sum_{i=1}^{m} k_{0} t_{i} \cdot \exp \left[-E_{a} / R T_{i}\right]\right]
$$

For a given temperature, according to above given equations we can get the quality change during a time period, which leads to the quality change $\Delta q$ for a time period $\tau$ and temperature $T$ : 


$$
\Delta q(\tau, T)=-k_{0} \tau \cdot \exp \left[-E_{a} / R T\right]
$$

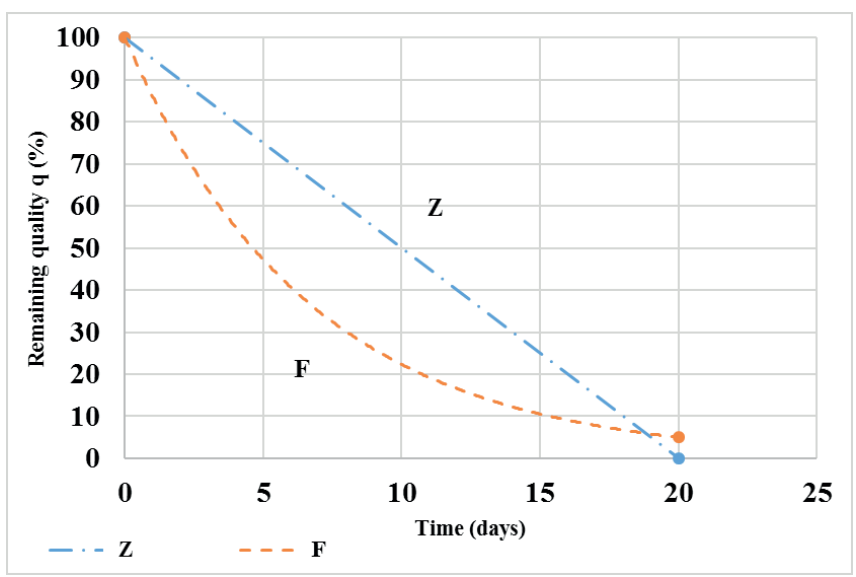

Fig. 1. Illustration of quality degradation

\section{PROBLEM OF PORT HINTERLAND INTERMODAL NETWORK SCHEDULING}

The intermodal network in food cold chain is illustrated in Fig. 2. Refrigerated containers with fresh food are shipped from foreign seaports to domestic ones. After discharge at the domestic ports, refrigerated containers can be transferred to distribution centres in inland cities by rail or truck (Fig. 3). Without rail facilities, refrigerated containers could also be transported from ports to inland cities all the way by truck.

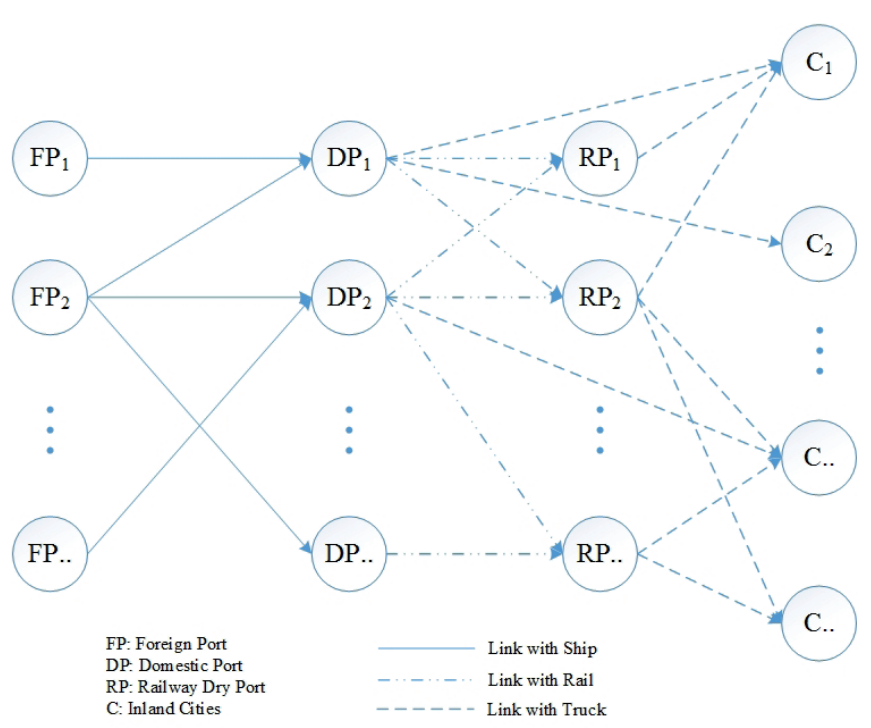

Fig. 2. The intermodal transport network of a container port hinterland

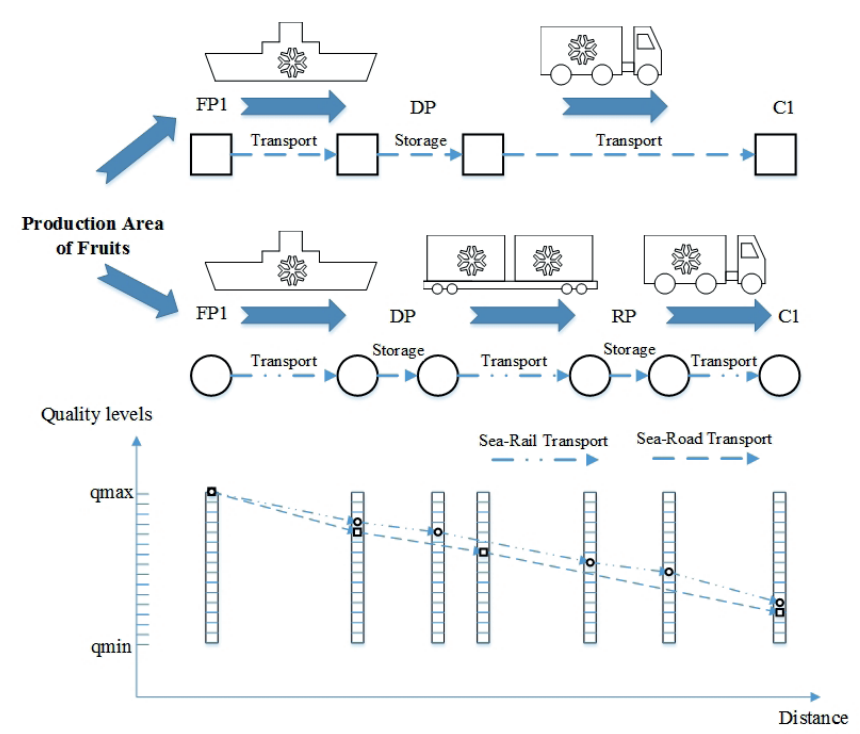

Fig. 3. The intermodal transport route from FP1 to C1 (see Notation, Sets)

\section{A BI-OBJECTIVE OPTIMIZATION MODEL}

\section{1) Notation}

\begin{tabular}{|c|l|}
\hline Indices & Description \\
\hline$i$ & Node index \\
\hline$i, j$ & Index of pair $(i, j)$, referring to an arc from node $i$ to node $j$ \\
\hline$q$ & Quality index \\
\hline$k$ & Temperature index \\
\hline
\end{tabular}

\begin{tabular}{|c|l|}
\hline Sets & Description \\
\hline$F P$ & Set of foreign ports \\
\hline$D P$ & Set of domestic ports \\
\hline$R P$ & Set of railway dry ports \\
\hline$C$ & Set of inland cities \\
\hline$N$ & Set of all nodes: $N=F P \cup D P \cup R P \cup C$ \\
\hline$A$ & $\begin{array}{l}\text { Set of all arcs: } A=A_{F P D P} \cup A_{D P R P} \cup A_{R P C} \cup A_{D P C} \text {, for each } \\
\left(i, j \in A_{X Y}\right),(i, j) \text { denotes the arc from } i \in X \text { and } j \in Y \text {, and } \\
X, Y \in\{F P, D P, R P, C\}\end{array}$ \\
\hline
\end{tabular}

Transport cost minimization and quality degradation minimization are included in the objective of this model. In actual realities, transport cost and quality degradation should be used to deal with the optimization by decision makers.

\begin{tabular}{|c|l|}
\hline $\begin{array}{c}\text { Decision } \\
\text { variable }\end{array}$ & Description \\
\hline$f n_{i, j, q, k}$ & $\begin{array}{l}\text { Flow quantities in TEU on arc }(i, j) \text { with temperature } \\
\text { level } k \text {, quality level } q \text { at the starting node } i,(i, j) \in A\end{array}$ \\
\hline Parameter & Description \\
\hline$G$ & $\begin{array}{l}\text { Average } \mathrm{CO}_{2} \text { emission limitation of this network per TEU } \\
\text { in kg }\end{array}$ \\
\hline$u_{i, j}$ & Distance from node $n_{i}$ to $n_{j}$ in $\mathrm{km},(i, j) \in A$ \\
\hline
\end{tabular}




\begin{tabular}{|c|c|}
\hline Parameter & Description \\
\hline$f_{i, j, k}$ & $\begin{array}{l}\text { Cost for transporting one TEU per } \mathrm{km} \text { on } \operatorname{arc}(i, j) \text { at } \\
\text { temperature level } k,(i, j) \in A\end{array}$ \\
\hline $\mathrm{CHC}_{i}$ & $\begin{array}{l}\text { Container handing cost in node } n_{i} \text { per TEU, } \\
n_{i} \in D P \cup R P\end{array}$ \\
\hline$g_{i, \mathrm{k}}$ & $\begin{array}{l}\text { Cooling cost for facility } i \text { at temperature level } k, \\
n_{i} \in D P \cup R P\end{array}$ \\
\hline$S F_{i}$ & Cost for storing one TEU in facility $i, n_{i} \in D P \cup R P$ \\
\hline$C S$ & $\begin{array}{l}\text { Cost for import container per TEU, including customs } \\
\text { clearance cost, container inspection fee, document fee, } \\
\text { and port security fee, etc. }\end{array}$ \\
\hline$C E Q_{i, j, k}$ & $\begin{array}{l}\text { Transportation } \mathrm{CO}_{2} \text { emission from node } n_{i} \text { to with } \\
\text { temperature } \mathrm{k} \text { in } \mathrm{kg} \text { per TEU, }(i, j) \in A\end{array}$ \\
\hline$C E S_{i, k}$ & $\begin{array}{l}\text { Storage } \mathrm{CO}_{2} \text { emission in node } n_{i} \text { with temperature } k \text { per } \\
\text { TEU, } n_{i} \in D P \cup R P\end{array}$ \\
\hline$\Delta q_{k}$ & $\begin{array}{l}\text { Quality degradation with temperature } k \text { per TEU per } \\
\text { hour }\end{array}$ \\
\hline$\Delta q_{i, k}$ & Quality degradation in facility $i, n_{i} \in D P \cup R P$ \\
\hline$\Delta q_{i, j, k}$ & Quality degradation on $\operatorname{arc}(i, j),(i, j) \in A$ \\
\hline$q_{0}$ & Initial quality \\
\hline$q_{\min }$ & Minimum quality level for products \\
\hline$S P M_{i}$ & Container supply quantity of node $n_{i}$ in TEU, $n_{i} \in F P$ \\
\hline$D M M_{i}$ & Container demand quantity of node $n_{i}$ in TEU, $n_{i} \in C$ \\
\hline$C A P_{i}$ & $\begin{array}{l}\text { Container throughput capacity of node } n_{i} \text { in TEU, } \\
n_{i} \in D P \cup R P\end{array}$ \\
\hline$T T P_{i j}$ & $\begin{array}{l}\text { Transportation time from node } n_{i} \text { to } n_{j} \text { in hours per } \\
\text { TEU, }(i, j) \in A\end{array}$ \\
\hline THT $_{i}$ & $\begin{array}{l}\text { Container handling time in node } n_{i} \text { per TEU, } \\
n_{i} \in D P \cup R P\end{array}$ \\
\hline$T S T_{i}$ & $\begin{array}{l}\text { Container storage time in node } n_{i} \text { per TEU, } \\
n_{i} \in D P \cup R P\end{array}$ \\
\hline
\end{tabular}

\section{2) Model assumptions}

To facilitate the modelling, we make the following assumptions:

- The goods in different pallets in one refrigerated container are in the same temperature.

- There are only one-way (inbound) flows for the intermodal network in food cold chain.

- There is sufficient capacity of transportation market to meet the demand of available vehicles for refrigerated container transport.

- The uncertainty of quality loss for the items in port area is ignored. Although there are some probable situations leading to quality loss during loading, intra-port transporting, switching-on/off the container to/from an electricity source, veterinary and custom inspection (Filina-Dawidowicz, 2014), container handlings in port area during intermodal transportation are relatively consistent.

\section{3) Model formulation}

Two objective functions:

$$
\begin{aligned}
\text { MinimiseTrans } C=\left(\begin{array}{l}
\sum_{k} \sum_{q} \sum_{(i, j) \in A} f n_{i, j, q, k} \times u_{i, j} \times f_{i, j, k} \\
+\sum_{k} \sum_{q} \sum_{(i, j) \in A} f n_{i, j, q, k} \times\left(C H C_{i}+C H C_{j}\right) \\
+\sum_{k} \sum_{q} \sum_{(i, j) \in A}\left(g_{i, \mathrm{k}} \times f n_{i, j, q, k}+S F_{i} \times f n_{i, j, q, k}\right) \\
+\sum_{k} \sum_{q} \sum_{(i, j) \in A \text { APPP }} f n_{i, j, q, k} \times C S
\end{array}\right) \div \sum_{i \in F} S P M_{i} \\
\text { MinimiseQualD }=\left(\begin{array}{l}
\sum_{k} \sum_{q} \sum_{(i, j) \in A} f n_{i, j, q, k} \times \frac{\Delta q_{i, j, k}}{q_{0}} \\
+\sum_{k} \sum_{q} \sum_{(i, j) \in A_{D P C} \cup A_{D P R P} \cup A_{R P C}} f n_{i, j, q, k} \times \frac{\Delta q_{i, k}}{q_{0}}
\end{array}\right) \div \sum_{i \in F} S P M_{i}
\end{aligned}
$$

with the constraints:

$$
\begin{aligned}
& \sum_{k} \sum_{q} \sum_{(i, j) \in A} f n_{i, j, q, k}=S P M_{i}, \quad \forall n_{i} \in F P \\
& \sum_{k} \sum_{q \geq q_{\min }} \sum_{(i, j) \in A} f n_{i, j, q, k}=D M M_{j}, \quad \forall n_{j} \in C \\
& \sum_{k} \sum_{q} \sum_{(i, j) \in A} f n_{i, j, q, k} \leq C A P_{i}, \quad \forall n_{i} \in D P \cup R P \\
& \sum_{k} \sum_{q} \sum_{(i, j) \in A}\left(\left(C E Q_{i, j, k}+C E S_{i, k}\right) \times f n_{i, j, q, k}\right) \div \sum_{i \in F} S P M_{i} \leq G \\
& \sum_{k} \sum_{i} f n_{i, j, q, k}=\sum_{k} \sum_{l} f n_{j, l, q-\Delta q_{j, k}-\Delta q_{j, j, k}, k}, \quad n_{i} \in F P \cup D P \cup R P, \forall n_{j} \in D P \cup R P \quad \forall q \\
& \Delta q_{i, k}=\left(T H T_{i} \times 2+T S T_{i}\right) \times \Delta q_{k}, \quad \forall n_{i} \in D P \cup R P \\
& \Delta q_{i, j, k}=T T P_{i j} \times \Delta q_{k}, \forall(i, j) \in A \\
& f n_{i, j, q, k} \in Z^{+}, \forall(i, j) \in A, \forall q, \forall k \in\left\{k_{1}, k_{2}, \ldots, k_{n}\right\}
\end{aligned}
$$

are formulated.

\section{4) Corresponding explanations}

The model can be applied to the intermodal transportation network design in food cold chain. We take the inbound container flows in the formulation of this model. The objective function (8) minimizes unit costs of refrigerated containers flowing through the network, which includes costs of: transportation, refrigeration, terminal handling , storage and customs clearance. The objective function (9) minimizes total unit quality degradation including the loss in transportation and storage. The definition of average quality degradation is used in this model. The total quality degradation is the sum of loss of food in each refrigerated container routing through all the network. Then the total loss is divided by the total container amount to get the unit quality degradation. The constraint (10) and (11) are supply and demand constraints of refrigerated containers. The constraint (12) specifies the capacity of each transport nodes. The constraint (13) represents the $\mathrm{CO}_{2}$ emission restrictions regulated by the government. The constraint (14) reflects the 
balance of cargo in flows and out flows at each node with quality degradation. The constraint (15) and (16) represent the quality degradation in a node and on an arc, respectively. The constraint (17) is the non-negativity constraint and integer restriction on the decision variables.

Similar to the viewpoint about capacity constraint expressed by H.J. Kim et al. (2008), we calculate the capacity of each domestic port by:

$$
C A P_{i}=\alpha_{i} \times C A P_{i}^{*}
$$

where $\alpha_{i}$ is the proportion of the cargo volume related to the intermodal transport among the total throughput at port $i$ and $C A P_{i}^{*}$ is the capacity corresponding to the transport of refrigerated containers of the port gotten after removing the trans-shipment cargoes.

This model is a bi-objective MILP problem including minimizing cost and quality degradation simultaneously and the $\mathrm{CO}_{2}$ emission requirements are set as a constraint in this model. The model was implemented in IBM ILOG CPLEX Optimization Studio 12.6 which is an optimization software program. Though large-scale cases need some meta-heuristic algorithms, most medium or small-size problems can be solved directly and efficiently by the CPLEX solver. The test runs were performed on a 3.50Ghz Xeon PC (with 16.0 GB RAM). The network resulted in a problem instance with tens of thousands of constraints and a few ten thousand variables (around 1500 integer) and was solvable well within limits acceptable for decision support in the industrial practice.

\section{MODEL APPLICATION AND ILLUSTRATIVE CASE STUDY}

In this section a case study on the refrigerated container cargo shipment in China is performed. As China strives to achieve more regional cooperation, its "Belt and Road" initiative will not only drive domestic development but will also influence its foreign policy. At sea, it will focus on jointly building smooth, secure and efficient transport routes connecting major sea ports and increase connectivity of customs clearance, reloading and multimodal transport between countries.

In this case we set the hinterland area of Dalian Port and Yingkou Port in Northeast China as the backyard of our study. As the most important container port in Northeast China, Dalian Port cooperates with more than 100 container shipping lines. Over 90 percent of the international containers in three north-eastern provinces need to be trans-shipped in Dalian Port. Not far away from Dalian Port, Yingkou Port was ranked as the $9^{\text {th }}$ container port since 2015 . We choose two domestic ports, Dalian Port and Yingkou Port, as an example. Rapid container traffic growth has taken place in the two ports over the past ten years. In this example two foreign ports , i.e. Laem Chabang and Manila are involved in China's international cold chain trade for bananas. According to the hinterland situation, we include two main inland transport modes, namely, truck and rail.

The selected hinterland areas of Dalian and Yingkou ports include Liaoning Province, Jilin Province and Heilongjiang Province. Nine big cities are chosen as inland city nodes. Based on the current situation of transportation infrastructure in Northeast China, we consider two railroad dry ports in Shenyang and Changchun. Data on distance parameters were collected from "SeaRates.com", "www.12306.cn" and "www.amap.com".

We assume that refrigerated container is $100 \%$ laden for import, and customs clearance cost amounts to $\$ 100$ per TEU. Other port handling cost is $\$ 160$ per TEU. Every inland city has its own demand in accordance with the different urban development level. Other parameters are given in Tab. 1.

Tab. 1. Transport parameters

\begin{tabular}{|l|c|c|c|}
\hline \multicolumn{1}{|c|}{ Mode } & Ship & Rail & Truck \\
\hline Variable transportation cost $(\$ / \mathrm{km})$ & 0.2 & 0.5 & 1.5 \\
\hline Average speed $(\mathrm{km} / \mathrm{h})$ & 40 & 40 & 60 \\
\hline $\mathrm{CO}_{2}$ footprint $(\mathrm{kg} / \mathrm{ton} \times \mathrm{km})$ & 0.084 & 0.208 & 0.796 \\
\hline
\end{tabular}

\section{QUALITY DEGRADATION}

Investing more resources in preservation efforts, by using a faster transportation mode or lower setting temperature, helps to keep quality degradation to a minimum (Cai et al., 2010). Although palletized bananas have been mainly transported on specialized vessels in the past, the transportation mode is shifting to refrigerated containers on shipping companies' vessels, which allows to take a more flexible reaction to fluctuating market volumes. For bananas, colour and weight are two important factors determining quality, green life and market value. According to the quality degradation of fruits ( see Sec. 2.1), the quality is a linear function of temperature. The optimum temperature range for bananas is between $10{ }^{\circ} \mathrm{C} \sim 15^{\circ} \mathrm{C}$. The green life period of bananas for each temperature option (take $11^{\circ} \mathrm{C}$ , $13^{\circ} \mathrm{C}$ and $15^{\circ} \mathrm{C}$ just to distinguish the effect of different temperature on cost and $\mathrm{CO}_{2}$ emission in the optimum range) is shown in Tab. 2 (Jedermann et al., 2014).

Tab. 2. Estimated quality degradation for bananas at different temperature levels

\begin{tabular}{|l|c|c|c|}
\hline \multicolumn{1}{|c|}{ Temperature $\left({ }^{\circ} \mathrm{C}\right)$} & 11 & 13 & 15 \\
\hline Green life period (days) & 52 & 45 & 38 \\
\hline Quality degradation per day $(\Delta q)$ & $0.96 \%$ & $1.104 \%$ & $1.316 \%$ \\
\hline
\end{tabular}

\section{RELATIVE COOLING COST AND CO FOOTPRINT}

The cost of transportation depends on the setting temperature. We take the thermal characteristics of cooling processes into consideration in order to determine the cost. The coefficient of performance (COP) for refrigeration is calculated as follows (Wang, 2000).

$$
C O P=\frac{Q_{L}}{W}=\frac{T_{L}}{T_{H}-T_{L}}
$$


Where $W$ is the input energy, $Q_{L}$ - the amount of heat transferred from a lower temperature environment to a higher one, $T_{H}$ - higher temperature and $T_{L}$ - lower temperature - both measured in Kelvin. The COP means that, for each unit of energy drawn from an electricity source, the coolant can absorb as much as COP units of heat from the inside of the refrigerator. For example, if $T_{H}=298 \mathrm{~K}\left(25^{\circ} \mathrm{C}\right)$, and $T_{L}=284 \mathrm{~K}\left(11^{\circ} \mathrm{C}\right)$, then COP is 20.29 .

If we assume the cost of electric energy at $11^{\circ} \mathrm{C}$ equal to 1 , then the relative cost at other temperature can be calculated by multiplying the cost with the ratio of COP. For instance, with the COP at $11^{\circ} \mathrm{C}(20.29)$ and the $\mathrm{COP}$ at $13^{\circ} \mathrm{C}$ (23.83), we get the ratio of $20.29 / 23.83=0.85$. The results for other temperature levels are shown in Tab. 3.

Tab. 3. The relative transportation cost and $\mathrm{CO}_{2}$ footprint values for different temperature values, using $11^{\circ} \mathrm{C}$ as a reference

\begin{tabular}{|l|l|l|l|}
\hline Temperature $\left({ }^{\circ} \mathrm{C}\right)$ & 11 & 13 & 15 \\
\hline Relative transportation costs & 1 & 0.85 & 0.70 \\
\hline Relative $\mathrm{CO}_{2}$ footprint & & & \\
\hline
\end{tabular}

\section{THE SCENARIO WITH BI-OBJECTIVE OPTIMIZATION}

To analyze the trade-offs between transport cost and quality degradation, we give the results of the bi-objective optimization shown in Fig. 4, 5 and 6. When transport cost is the only objective, the railway transport mode with the highest setting temperature which generates the lowest $\mathrm{CO}_{2}$ emission is the most preferred one. When quality degradation is the only objective, the truck transport mode with the lowest setting temperature which generates the highest $\mathrm{CO}_{2}$ emission is the most preferred.

The usage rate of truck is still higher while the usage rate of train is relatively low because many cities do not have railway links to domestic ports or the capacity of existing railway dry ports is limited with the growing rail-sea intermodal transportation volumes. The inland transportation network of Dalian Port and Yingkou Port is composed of railway, highway and state roads, which covers the whole Northeast China hinterland. The capacity of railway dry port will keep pace with the increasing of transportation demand for containers according to the economic and social development planning.

In the sea leg, optimization objectives also affect the route for cargo. Dalian Port is an integral part of Dalian Northeast Asian International Shipping Centre. For import containers to the port hinterland, many shipping lines call Dalian Port first and then Yingkou Port, or link Dalian and Yingkou ports with feeder services. If a customer needs to receive cargoes at a lower quality loss, container must be discharged at Dalian Port and then trucked to Yingkou, otherwise his containers can be discharged at Yingkou Port.

\section{SENSITIVITY ANALYSIS OF CO $\mathrm{CO}_{2}$ EMSSION RESTRICTIONS}

According to Sec. 2.3, G represents the average $\mathrm{CO}_{2}$ emission limitation per TEU which reflects the restriction on $\mathrm{CO}_{2}$ emission. In order to illustrate the impact of $\mathrm{G}$ value, we obtain modelling results at four sets of $\mathrm{G}$ value. In $\mathrm{CO}_{2}$ requirements I, II and III, G values are set to $20830 \mathrm{~kg}$, $22370 \mathrm{~kg}$ and $23910 \mathrm{~kg}$, respectively. In $\mathrm{CO}_{2}$ requirements IV, G value is set to $32040 \mathrm{~kg}$ or more. When $\mathrm{G}$ value is greater than $32040 \mathrm{~kg}$ (When this result is obtained, we take some other small values at equal intervals just to contrast the effect of $\mathrm{CO}_{2}$ emission on modelling results), the change of $\mathrm{G}$ value will not impact the Pareto Frontier.

We can note that the usage of train increases and the setting temperature rises when $\mathrm{G}$ value decreases. The usage of truck increases and the setting temperature decreases when $G$ value increases. This finding is in conformity with the common sense that train is more environmentally friendly than truck and higher temperature causes less greenhouse emissions.

It is noted that a small change in $\mathrm{CO}_{2}$ emissions will have a significant effect on the results. The sea transport distance takes a primary share in the total intermodal chain's mileage because majority of $\mathrm{CO}_{2}$ emission is from the sea transport. Thus, addressing environmental protection into intermodal network design, we can reduce the truck mileage for inland transport, which can also save cost. However there must be done substantial improvements in inland intermodal transport infrastructures, including railways and dry ports.

Tab. 4. Transport quantity via railroad ports

\begin{tabular}{|l|c|c|c|c|c|}
\hline Railway dry & Capacity & \multicolumn{5}{|c|}{ Usage (TEU) } \\
\cline { 3 - 6 } port & $($ TEU) & G=20830kg & G=22370kg & G=23910kg & G $\geq 32040 \mathrm{~kg}$ \\
\hline Shenyang & 600 & 600 & 0 & 0 & 0 \\
\hline Changchun & 450 & 450 & 450 & 209 & 0 \\
\hline Total & 1050 & 1050 & 450 & 209 & 0 \\
\hline
\end{tabular}

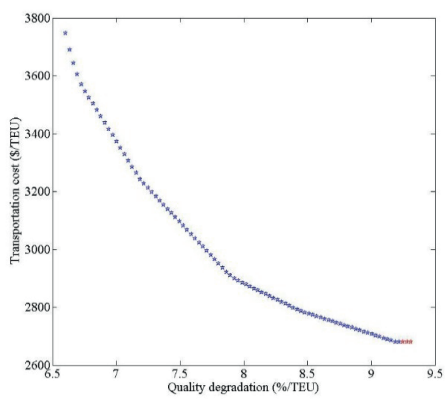
$\mathrm{G}=20830 \mathrm{~kg}, \mathrm{~T}=15.0^{\circ} \mathrm{C}$

Fig. 4. Modelling results at $\mathrm{CO}_{2}$ Emission Constraint $I(\mathrm{G}=20830 \mathrm{~kg})$

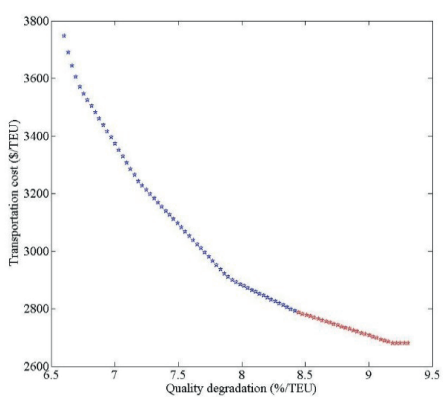
$\mathrm{G}=22370 \mathrm{~kg}, \mathrm{~T}=14.0^{\circ} \mathrm{C}$

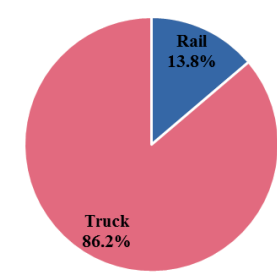

Fig. 5. Modelling results at $\mathrm{CO}_{2}$ Emission Constraint II $(\mathrm{G}=22370 \mathrm{~kg})$ 

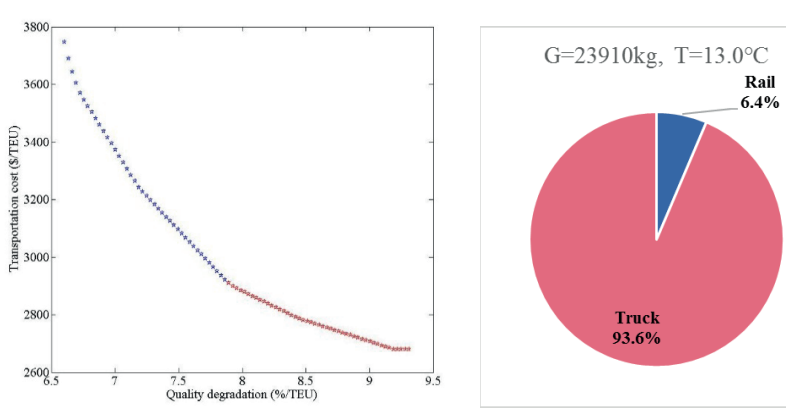

Fig. 6. Modelling results at $\mathrm{CO}_{2}$ Emission Constraint $I I I(G=23910 \mathrm{~kg})$

\section{FITTING ANALYSIS IN AMBIENT TEMPERATURES}

Based on the description given in Sec. 3.2 , it is known that we use $25^{\circ} \mathrm{C}$ as the ambient temperature. However, there will be different ambient temperatures in different seasons with global periodic climate change. Relative transportation costs and relative $\mathrm{CO}_{2}$ footprint in different ambient temperatures are shown in Tab. 5 .

Fig. 7 summarizes the results for four different ambient temperatures. It clearly shows that the increase in ambient temperature leads to the increase in cost under the same average quality degradation. The difference between the ambient temperature and the temperature in refrigerated containers has an obvious effect on cost because the higher the temperature difference the more energy burnt by the vehicle.

Tab. 5. The relative transportation cost and $\mathrm{CO}_{2}$ footprint values, using $11^{\circ} \mathrm{C}$ as the reference for different ambient temperatures

\begin{tabular}{|c|c|c|c|c|}
\hline \multicolumn{2}{|c|}{ Ambient temperature $\left({ }^{\circ} \mathrm{C}\right)$} & \multicolumn{3}{|c|}{ Setting Temperature $\left({ }^{\circ} \mathrm{C}\right)$} \\
\cline { 2 - 5 } & 21 & 11 & 13 & 15 \\
\hline \multirow{2}{*}{$\begin{array}{c}\text { Relative } \\
\text { transportation costs or } \\
\text { Relative } \mathrm{CO}_{2} \text { footprint }\end{array}$} & 23 & 1 & 0.83 & 0.59 \\
\cline { 2 - 5 } & 25 & 1 & 0.85 & 0.70 \\
\cline { 2 - 5 } & 27 & 1 & 0.87 & 0.74 \\
\hline
\end{tabular}

The outlining characters of the three-dimensional curved surface are analyzed. Based on the fitting curved surface, a new calculating method for the cost is presented ( Eq. 20 ).

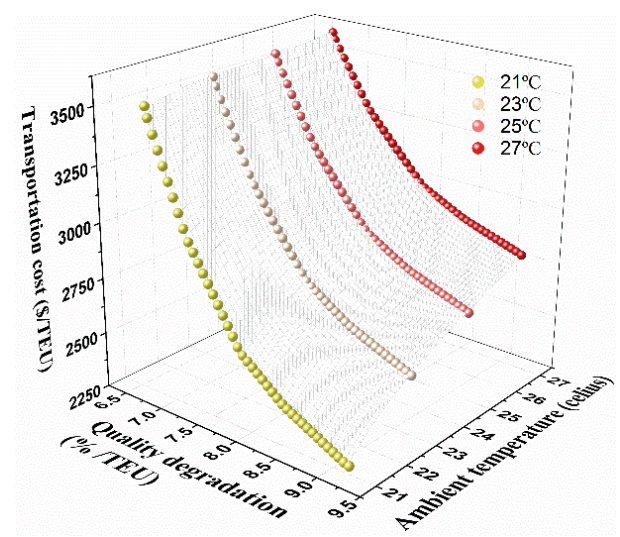

Fig. 7. Modelling results for different ambient temperatures

$$
\begin{aligned}
& Z=A+B x+C / y+D x^{2}+E / y^{2}+F x / y \\
& +G x^{3}+H / y^{3}+I x / y^{2}+J x^{2} / y
\end{aligned}
$$

where : $\mathrm{Z}$ is the transportation cost, $\mathrm{x}$ - the average quality degradation and $\mathrm{y}$ - the ambient temperature. $\mathrm{A}, \mathrm{B}, \mathrm{C}, \mathrm{D}, \mathrm{E}$, F, G, H, I, J are parameters of the fitting equation (20). The fitting parameters of the three-dimensional curved surface are shown in Tab. 6.

Tab. 6. Fitting parameters of three-dimensional curved surface

\begin{tabular}{|c|c|c|c|}
\hline $\mathrm{A}$ & $\mathrm{B}$ & $\mathrm{C}$ & $\mathrm{D}$ \\
\hline $3.33 \times 10^{4}$ & $-5.29 \times 10^{3}$ & $-8.79 \times 10^{5}$ & 773.88 \\
\hline $\mathrm{E}$ & $\mathrm{F}$ & $\mathrm{G}$ & $\mathrm{H}$ \\
\hline $3.20 \times 10^{7}$ & $-1.04 \times 10^{5}$ & -38.37 & $-2.39 \times 10^{7}$ \\
\hline $\mathrm{I}$ & $\mathrm{J}$ & $\mathrm{R}^{2}$ & \\
\hline$-3.03 \times 10^{5}$ & $7.23 \times 10^{3}$ & 0.994 & \\
\hline
\end{tabular}

\section{CONCLUSIONS AND FUTURE RESEARCH}

This research has provided a novel approach to the intermodal network design problem for refrigerated container shipment considered from the tactical level point of view, based on an optimization model. The shippers need to know how to optimize transport planning based on customer requirements and transportation infrastructure. In the market driven business environment, they have to optimize total cost and also to meet quality requirement given by customers. Especially for high value-added products, they have to take fully the influence of temperature and time on the quality of commodities into account. In the meantime, they are required to comply with $\mathrm{CO}_{2}$ emission restrictions as commodity refrigeration produces more $\mathrm{CO}_{2}$ emission during transportation. Roads and railways are the most common modes for container land transportation with their imperfections and suitability. As discussed in the former sensitivity analysis, the $\mathrm{CO}_{2}$ emission restriction for cold chain transportation in the intermodal network can be adjusted to accommodate different situations. First, the shippers should utilize railways as the primary transportation mode and set the higher temperature to lower cost and $\mathrm{CO}_{2}$ emissions whenever inland railways are available. Second, they are recommended to use trucks and set lower temperature selectively when quality of commodities is a major concern from the side of customers. Third, tighter environment regulations on $\mathrm{CO}_{2}$ emissions favour rail transport and higher temperature setting, and a little change in the $\mathrm{CO}_{2}$ emission restriction will have a significant impact on the range of feasible solutions. Thus, the shipper ought to adopt a better approach by flexible taking cost, quality and $\mathrm{CO}_{2}$ emission into consideration for the intermodal network planning. The preference choices of the model for the cold chain design (Sea-Rail Transport and Sea-Road Transport) are a combination of these factors 
for the mutual relationship among transportation modes, quantities and setting temperatures.

Furthermore, shippers can use the optimization model for investment and service planning before they enter a new market. In the numerical example, Harbin-Dalian Railway, G1 Highway, G2 Highway and other important passages serve as a corridor linking coastal ports in Liaoning Province and Northeast China hinterland. Actually, the Chinese government has realized that insufficient transport infrastructure hinders the economic development of Northeast China. The central committee of the Communist Party of China, announced a plan to revitalize the old industrial base of Northeast China, largely focusing on its transport facilities. Li Keqiang stressed that the government should invest more in public facilities such as transport, water projects and railways, and also called for innovation in investment and financing - to attract more social investment.

There are some contributions made by this research not only to the academic field but also the transportation industry. As an academic contribution, this model fills the gaps in the subject-matter literature, because it optimizes port- hinterland intermodal flows of refrigerated containers considering both cost and quality degradation. Moreover, this study is distinctive from the previous literature in a way that it quantifies the influence of $\mathrm{CO}_{2}$ emission in different setting temperatures on intermodal network planning. Also, the numerical example provides an illustration of the intermodal network planning in Northeast China. Furthermore, the model can offer a useful reference for other regions with the demand for different imported food which requires an uninterrupted cold chain during the transportation and storage. The primary contribution of this paper is that the model is beneficial not only to shippers and customers for the novel service design, but also offer insights for the governmental policy-makers to attract attention to developing inland transport infrastructure when considering intermodal transportation.

There are also some limitations in this study. On one hand, the uncertainty factors, such as demand, supply and transit time have not been considered in this study. On the other hand, in this model we do not combine the inbound and outbound container flows, which means that the developed formula represents only one-way flow. All of these issues are valuable research directions to be undertaken in the future.

\section{ACKNOWLEDGMENT}

The authors would like to acknowledge the support of National Natural Science Foundation of China ( Projects No. 51309049 and No. 51279026 ). In addition, we acknowledge the Research Centre for Port Development at Dalian University of Technology for partial funding and devices.

\section{REFERENCES}

1. FAO: FAO Statistical Yearbook 2014 (FAO ed.).

2. H. Min : International intermodal choices via chanceconstrained goal programming. Transportation Research Part A General. 25(6), 1991, pp.351-362.

3. FIannone and S Thore: An economic logistics model for the multimodal inland distribution of maritime containers. International Journal of Transport Economics. 37, 2010 , pp. 281-326.

4. W.F. Wang and W.Y. Yun : Scheduling for inland container truck and train transportation. International Journal of Production Economics. 143, 2013, pp. 349-356.

5. R . Zhang, W.Y. Yun, H. Kopfer: Heuristic-based truck scheduling for inland container transportation. Or Spectrum. 32 , 2010, pp. 787-808.

6. C. Liao, P. Tseng and C. Lu: Comparing carbon dioxide emissions of trucking and intermodal container transport in Taiwan. Transportation Research Part D : Transport and Environment:,14, 2009, pp. 493-496.

7. X.J. Yang, J. Low and L.C. Tang: Analysis of intermodal freight from China to Indian Ocean: A goal programming approach. Journal of Transport Geography, 19, 2011, pp. 515-527.

8. R.Y. Zhang, W.Y. Yun , I.K. Moon: Modelling and optimization of a container drayage problem with resource constraints. International Journal of Production Economics,133, 2011, pp. 351-359.

9. J. Lam and Y. Gu : A market-oriented approach for intermodal network optimisation meeting cost, time and environmental requirements. International Journal of Production Economics,171, 2011, pp. 266-274.

10. M. Rahimi, A. Asef-Vaziri and R. Harrison: An Inland Port Location-Allocation Model for a Regional Intermodal Goods Movement System. Maritime Economics \& Logistics, 10,2010 , pp. 362-379.

11. W.B. Fitzgerald, O. Howitt, I.J. Smith, et al. : Energy use of integral refrigerated containers in maritime transportation. Energy Policy,39, 2011, pp. 1885-1896.

12. K. Vankerschaver, F. Willocx, C. Smout, et al. : Mathematical modelling of temperature and gas composition effects on visual quality changes of cut endive. Journal of Food Science, 61,1998, pp. 613. 
13. K. McDonald and D.W. Sun : Predictive food microbiology for the meat industry: a review. International Journal of Food Microbiology, 52 , 1999, pp. 1-27.

14. L. Lukasse and J.J. Polderdij : Predictive modelling of post-harvest quality evolution in perishables, applied to mushrooms. Journal of Food Engineering, 59, 2003, pp. 191-198.

15. H.J. Kim, Y.T. Chang, T.W. Lee, et al. : Optimizing the transportation of international container cargoes in Korea. Maritime Policy \& Management, 35, 2008, pp. 103-122.

16. Filina-Dawidowicz L. : Rationalization of servicing reefer containers in sea port area with taking into account risk influence. Polish Maritime Research, 21, 2014, pp. 76-85.

17. X.Q. Cai, J. Chen, Y.B. Xiao, et al. : Optimization and Coordination of Fresh Product Supply Chains with Freshness-Keeping Effort. Production and Operations Management, 19, 2010, pp. 261-278.

18. R .Jedermann, U. Praeger, M. Geyer, et al. : Remote quality monitoring in the banana chain. Philosophical Transactions of the Royal Society a-Mathematical Physical and Engineering Sciences, 372, 2014.

19. S.K. Wang : Handbook of Air Conditioning and Refrigeration. Ed.S.K. Wang, 2000.

\section{CONTACT WITH THE AUTHORS}

\section{Qianli Ma}

e-mail:qianlima@mail.dlut.edu.cn Dalian University of Technology Linggong Road, 116024 Dalian

\section{China}

\section{Wenyuan Wang}

e-mail:wangwenyuan@dlut.edu.cn Dalian University of Technology Linggong Road, 116024 Dalian

\section{China}

\section{Yun Peng}

e-mail:yun_peng@dlut.edu.cn Dalian University of Technology Linggong Road, 116024 Dalian

\section{China}

\section{Xiangqun Song} e-mail:sxqun@dlut.edu.cn Dalian University of Technology Linggong Road, 116024 Dalian

China 